\title{
STUDIES ON SIZE INHERITANCE IN NICOTIANA
}

\author{
E. M. EAST \\ Harvard University, Bussey Institution, Forest Hills, Massachusetts
}

[Received January 6, 1916]

As various writers have pointed out, all Mendelizing characters probably are dite to the interaction of several genes, and presumably every gene may exhibit several somatic effects, yet no one doubts that the Mendelian notation describes the inheritance of such things as color accurately and concisely. It is strange, therefore, that some geneticists still refuse to believe that the inheritance of size characters can be described in the same way, without further assumptions.

Various reasons are assigned for this disbelief.

It is held that one should not assume the absence of dominance, as has been done by those who have investigated size characters. But as a matter of fact, absolute dominance is rare. A heterozygous gene very seldom produces an effect identical with that of homozygous genes. Full dominance is the extreme, the limiting condition, not the common condition. Even with such simple and possibly superficial characters as colors, careful examination usually shows incomplete dominance.

A further misconception of the phenomenon of dominance is the objection to the assumption of genes having cumulative effects. As stated in the first sentence, most Mendelizing characters have been shown to be due to the interaction of several traceable factors, in addition to an ever present factorial residue of which nothing is known. This unexplored ground may be reduced in its extent by new mutations affecting the character in question, but proof can never be offered that it has been entirely eliminated. For the same reasons it follows that one should not assume that the simplicity of the known facts proves actual simplicity in the hereditary transmission of any character. This complexity in the germinal basis of characters, is, of course, general proof of the cumulation effect of genes, but in addition a specific case has recently been found in maize (HAYES and EAST, I9I5). When reciprocal crosses of "floury" and "flinty" maize races are made, the maternal endosperm character is dominant. This dominance has been proved to be due to the fact that the 
endosperm is produced by the union of two maternal and one paternal nuclei. Thus two genes of either kind dominate the effect of one.

The only other criticisms worthy of notice are directed against assumptions of gametic purity and of factorial constancy. As criticisms of the Mendelian interpretation of quantitative characters they come no nearer the mark, for they apply to Mendelism as a whole. ${ }^{1}$.

The true reason for objecting to the theory, therefore, seems to beas is often the case-that those who disapprove of it have not given it sufficient study to be convinced that any real evidence in its favor can be cited. For example, Castle (1914) says:

"When races are crossed that differ widely in size, the first filial $\left(F_{1}\right)$ generation is intermediate between the parents and often not more variable than one of the parent races. But the second filial $\left(\mathrm{F}_{2}\right)$ generation, though still intermediate, commonly shows increased variability, the range of which may even extend into or include the size range of one or both parent races. This increased variability of the $F_{2}$ generation is the only evidence of Mendelism in size crosses."

With this view I cannot agree. It is true that one may not expect dimorphic phenotypes in simple ratios in the $\mathrm{F}_{2}$ generation. Somatic appearance is not so highly correlated with genetic constitution that definite ratios always appear when characters like color are studied. Even in such cases one must prove the classification of the phenotypes by further breeding. By, carefully studying what actually occurs in simple and obvious Mendelian phenomena, however, the mathematical requirements where size characters are involved can be worked out. If these requirements are independent,-i.e., if they are not restatements of the same conditions, - and if the breeding facts meet them fairly and squarely, the case is good.

At least eight such requirements, most of which are independent mathematically, should be met by the pedigree-culture data when all populations succeeding the original cross are obtained by self-fertilization.

I. Crosses between individuals belonging to races which from longcontinued self-fertilization or other close inbreeding approach a homozygous condition, should give $\mathrm{F}_{1}$ populations comparable to the parental races in uniformity.

2. In all cases where the parent individuals may reasonably be presumed to approach complete homozygosis, $F_{2}$ frequency distributions arising from extreme variants of the $F_{1}$ population, should be practically

\footnotetext{
1 The question of the validity of these criticisms when directed against the entire
} Mendelian theory, is not under discussion.

Genetics 1: Mh 1916 
identical, since in this case all $\mathrm{F}_{1}$ variation should be due to external conditions.

3. The variability of the $F_{2}$ population from such crosses should be much greater than that of the $F_{1}$ population.

4. When a sufficient number of $F_{2}$ individuals are available, the grandparental types should be recovered.

5. In certain cases individuals should be produced in $\mathrm{F}_{2}$ that show a more extreme deviation than is found in the frequency distribution of

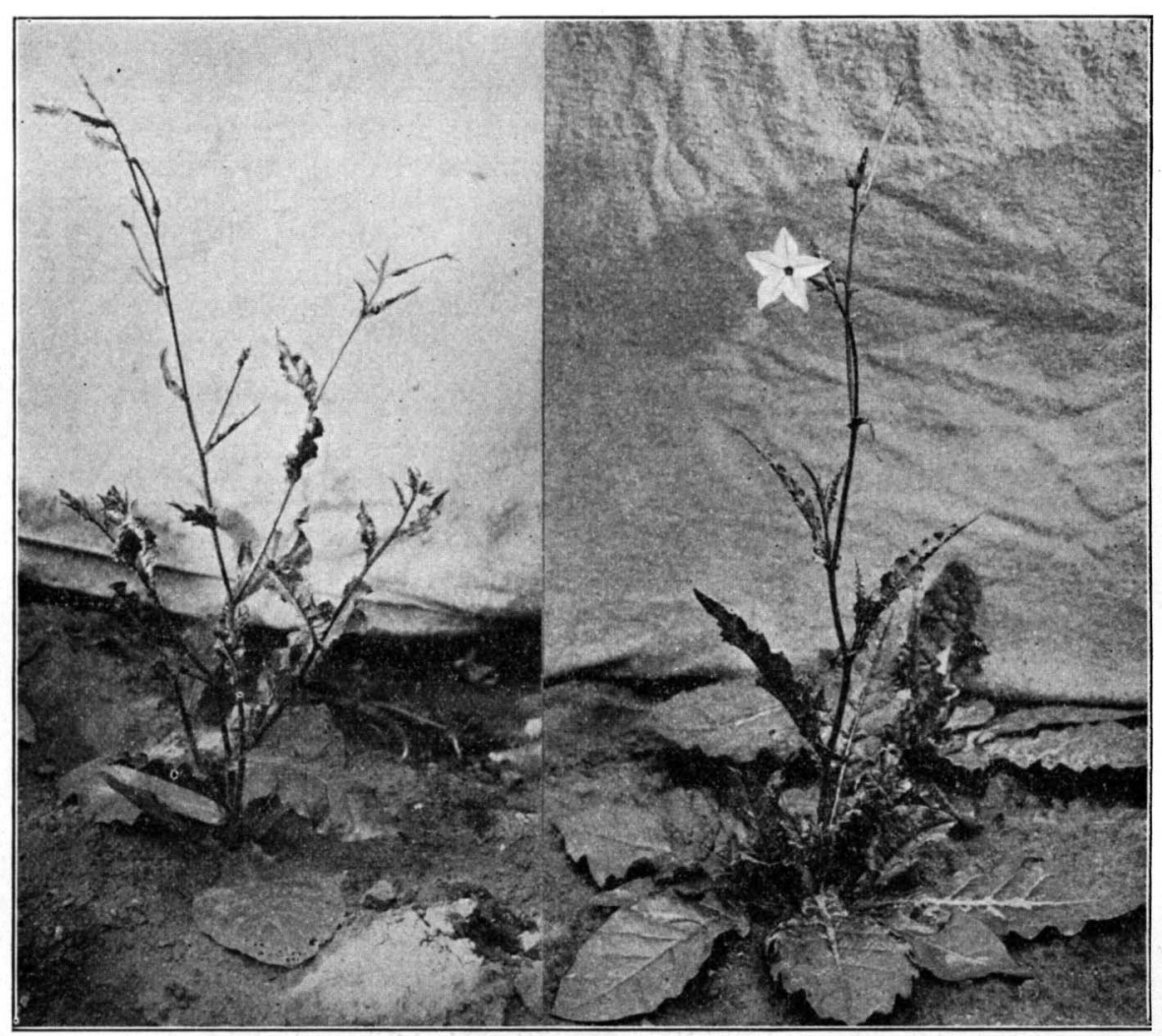

FIgURE I. At left, young plant of Nicotiana longiflora var. (383); at right, young plant of $N$. longiflora (330).

either grandparent. This phenomenon was predicted by the writer (EAst, I9IO) as an expected result of Mendelian recombination before actual cases had been discovered.

6. Individuals from various points on the frequency curve of an $\mathrm{F}_{2}$ population, should give $F_{3}$ populations differing markedly in their modes and means. 
7. Individuals either from the same or from different points on the frequency curve of an $\mathrm{F}_{2}$ population should give $\mathrm{F}_{3}$ populations of diverse variabilities extending from that of the original parents to that of the $\mathrm{F}_{2}$ generation.

8. In generations succeeding the $\mathrm{F}_{2}$, the variability of any family may be less but never greater than the variability of the population from which it came.

Not all of these eight conditions are met by the data to be presented

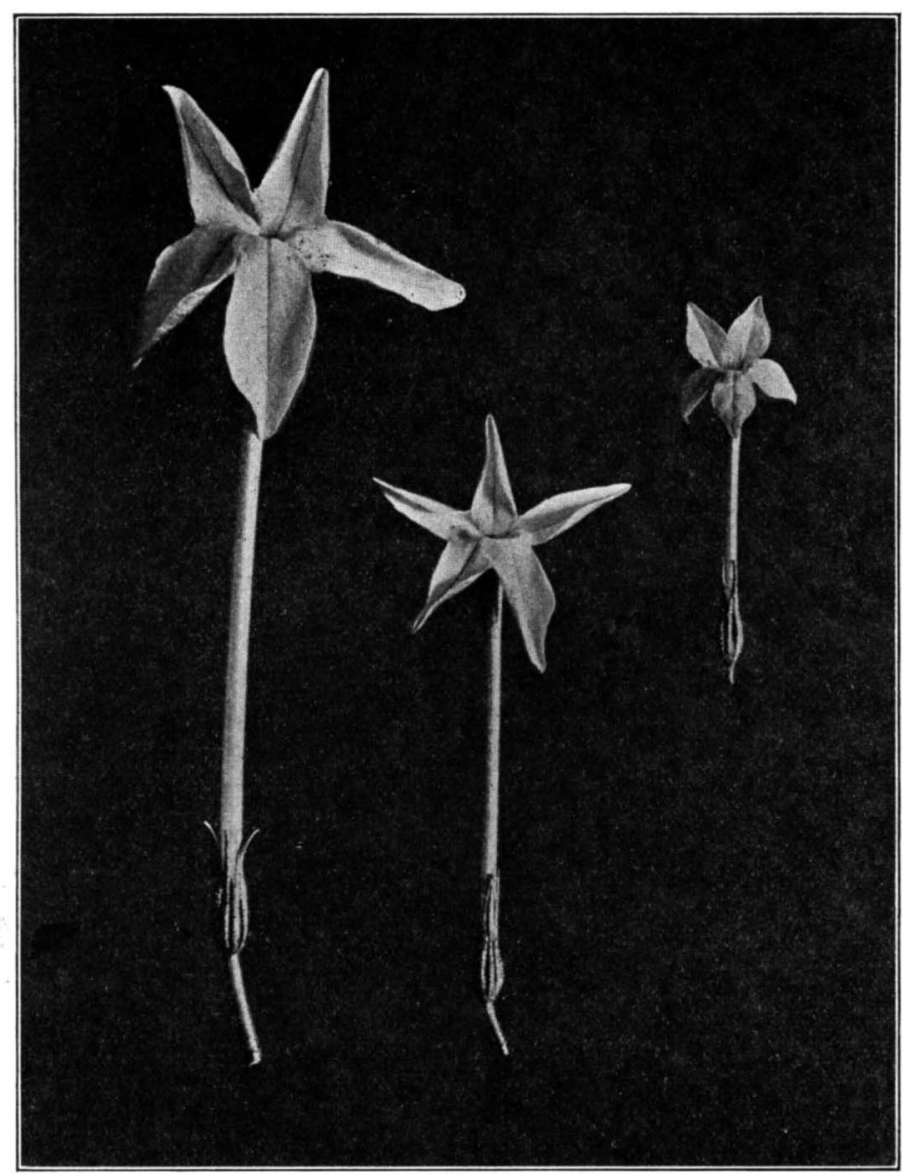

Figure 2. Average flowers of parents with an average flower of the $\mathrm{F}_{2}$ generation $(383 \times 330)$ in the center.

in this paper, but all of them have been met many times in the course of other experiments, and not one fact has been discovered directly opposed to them. 
The data to be considered here were obtained by measuring the length of the corolla in a cross between two varieties of Nicotiana longiflora Cav. The seed of No. 330, which is probably the type, was obtained from Prof. W. A. Setchell (see Setchell I9I2, pp. 2I-22). The seed of No. 383 was received from the Instituto Sperimentale per le Cultivazioni dei Tabacchi at Scafati, Italy, through the kindness of Dr. A. Splendore. It was known there as $N$. phumbaginifolia Viv., but seems to be merely a small variety of $N$. longiflora.

Each corolla length recorded is expected to represent the phenotype of a single plant. The method of recording them and the accuracy that

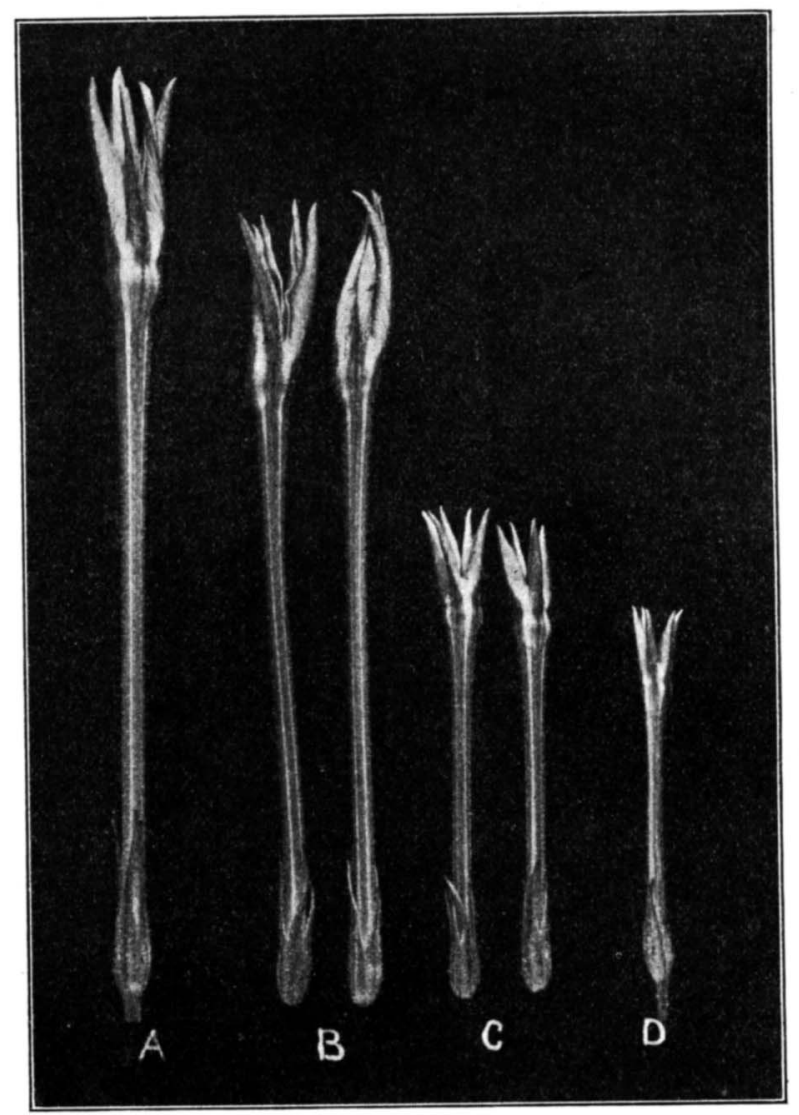

FIgURE 3. Average flowers of parents at A (330) and D (383); extreme segregates of the $\mathrm{F}_{2}$ generation at $\mathrm{B}$ and $\mathrm{C}$. 


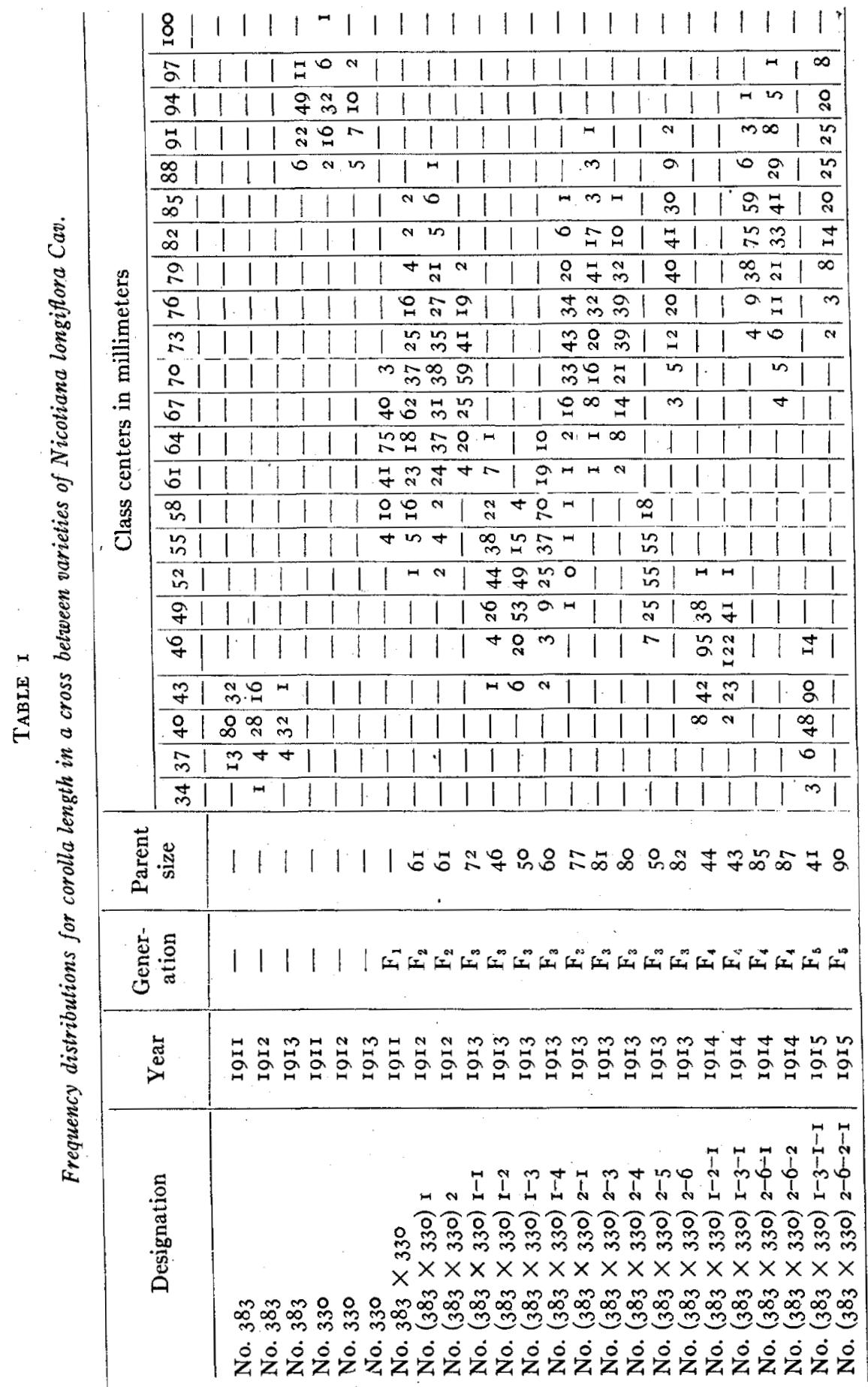


may be expected of the method have been discussed in another paper (EAST 1916).

Both of the varieties used as parents may reasonably be supposed to be homozygous in most of their characters for they are generally selfpollinated naturally. Whether either or both of them had been selfpollinated artificially before I obtained them is not known, but they had been self-pollinated for two generations after I received them before the cross was made. The crosses and the succeeding selfings gave full capsules, and the germination of the seeds was almost perfect.

As shown by the tables, if the frequency distributions of the pure varieties for 1913 are excluded on account of the small number of plants grown, the average mean of No. $3^{8} 3$ is $40.54 \mathrm{~mm}$ and of No. $330,93.30$ $\mathrm{mm}$. The species has corollas over twice the length of the variety. The average of both parents is $66.9 \mathrm{I} \mathrm{mm}$, and since the mean length of the $F_{1}$ generation is $63.53 \mathrm{~mm}$, it is clear that the vigor induced by heterozygosity, which was fairly well marked in the vegetative characters, had no effect on the flowers. This fact is in keeping with previous observations, since it has been shown that corolla length is very slightly influenced by external conditions, and that heterozygosity effects a result comparable to favorable external conditions.

The variability of the $F_{1}$ population appears to be exactly the mean of variety No. 383 (the more variable parent) for the two years I9II and IgI2, thotigh considerably higher than the variability of variety No. 330 for the same period. Theoretically one ought to expect this only when both parental varieties are completely homozygous, therefore the data might be supposed to show such a condition. But, while the two varieties used here probably approach a homozygows condition, the similarity of the two constants obtained is possibly more apparent than real. The measurements have been thrown into three-millimeter classes for convenience, but these classes are manifestly too large for small flowers like those of No. 383. If one-millimeter classes are used there is less distortion of the figures and the percentage variability is smaller. For this reason $I$ believe that it is fair to conclude that the variability of the $F_{1}$ population is slightly larger than that of either parent. The proponents of the Mendelian theory may maintain that this merely shows a slight degree of heterozygosity in the parents, therefore, while its opponents may see in the results indication of a slight increase in variability due to the cross itself. No one can object to this view when considered apart from other facts, but it should be pointed out that the difference to be accounted for is very small in either case. 
TABLE 2

Statistical constants of the frequency distributions shown in table 1 .

\begin{tabular}{|c|c|c|c|c|c|}
\hline Designation & - & $\begin{array}{l}\text { No. } \\
\text { Ind. }\end{array}$ & Mean & $\begin{array}{l}\text { S. D. } \\
\text { in } \mathrm{mm}\end{array}$ & $\begin{array}{c}\text { C. V. } \\
\text { in percent }\end{array}$ \\
\hline No. 383 -I9I I & & 125 & $40.46 \pm$. II & I. $75 \pm .07$ & $4 \cdot 33 \pm .18$ \\
\hline No. $383-\operatorname{Ig} 12$ & & 49 & $40.61 \pm .19$ & $2.00 \pm .14$ & $4.92 \pm .34$ \\
\hline No. 383 I9I 3 & & 37 & $39 \cdot 76 \pm .12$ & $1.09 \pm .09$ & $2.74 \pm .21$ \\
\hline No. 330 -IgII & & 88 & $93 \cdot 22 \pm .16$ & $2.29 \pm .12$ & $2.46 \pm .13$ \\
\hline No. $330-1912$ & & 57 & $93 \cdot 37 \pm .20$ & $2.23 \pm .14$ & $2.39 \pm .15$ \\
\hline No. 330 - 913 & & 24 & $92.12 \pm .37$ & $2.70 \pm .26$ & $2.93 \pm .30$ \\
\hline No. $(330 \times 383)$ & $F_{1}$ & I 73 & $63 \cdot 53 \pm .15$ & $2.9^{2} \pm . I I$ & $4.60 \pm .17$ \\
\hline No. $(330 \times 383)-1$ & $\mathbf{F}_{2}$ & $2 \mathrm{II}$ & $67.51 \pm .27$ & $5.9 \mathrm{x} \pm .19$ & $8.75 \pm .29$ \\
\hline No. $\left(33^{\circ} \times 383\right)-2$ & $\mathbf{F}_{2}$ & 2.33 & $69.7^{8} \pm .30$ & $6.79 \pm .21$ & $9.73 \pm .30$ \\
\hline No. $(330 \times 383) 1-1$ & $\mathrm{~F}_{3}$ & 170 & $73 \cdot 14 \pm .20$ & $3.82 \pm . x_{4}$ & $5.22 \pm .19$ \\
\hline No. $(330 \times 383) x-2$ & $\mathbf{F}_{3}$ & I43 & $53.47 \pm .21$ & $3.74 \pm .15$ & $6.99 \pm .28$ \\
\hline No. $(330 \times 383) 1-3$ & $F_{3}$ & I47 & $50.20 \pm .18$ & $3.17 \pm .12$ & $6.31 \pm .25$ \\
\hline No. $\left(330 \times 3^{83}\right) \mathrm{I}-4$ & $\mathbf{F}_{3}$ & 175 & $56.34 \pm .21$ & $4.07 \pm .15$ & $7.22 \pm .26$ \\
\hline No. $\left(33^{\circ} \times 383\right)_{2-1}$ & $\mathbf{F}_{3}$ & $\times 59$ & $73.04 \pm .27$ & $5.00 \pm .19$ & $6.85 \pm .26$ \\
\hline No. $(330 \times 383)_{2-3}$ & $\mathbf{F}_{3}$ & I43 & $76.34 \pm .29$ & $5.06 \pm .20$ & $6.63 \pm .26$ \\
\hline No. $\left(330 \times 3^{8} 3\right)^{2-4}$ & $\mathbf{F}_{\mathbf{3}}$ & 166 & $74.01 \pm .25$ & $4.85 \pm .18$ & $6.55 \pm .24$ \\
\hline No. $\left(330 \times 3^{83}\right)^{2-5}$ & $\mathbf{F}_{\mathbf{3}}$ & I60 & $52.97 \pm .16$ & $3.04 \pm . I I$ & $5 \cdot 74 \pm .22$ \\
\hline No. $(330 \times 383) 2-6$ & $\mathbf{F}_{3}$ & 162 & $80.20 \pm .25$ & $4 \cdot 76 \pm . I 8$ & $5 \cdot 93 \pm .22$ \\
\hline No. $(330 \times 383)$ I-2-I & $F_{1}$ & 184 & $45 \cdot 7 x \pm .12$ & $2.37 \pm .08$ & $5 \cdot 18 \pm .18$ \\
\hline No. $\left(330 \times 3^{83}\right) I^{-} 3^{-I}$ & $\mathbf{F}_{4}$ & $\mathbf{1} 89$ & $46.25 \pm .09$ & $1.87 \pm .06$ & $4.04 \pm .14$ \\
\hline No. $(330 \times 383) 2-6-1$ & $F_{4}$ & 195 & $82.25 \pm .16$ & $3 \cdot 30 \pm . \mathrm{II}$ & $4.01 \pm .14$ \\
\hline No. $(330 \times 383)^{2-6-2}$ & $\mathrm{~F}_{4}$ & 164 & $82.86 \pm .31$ & $5.83 \pm .22$ & $7.04 \pm .26$ \\
\hline No. $\left(330 \times 3^{8}\right) I^{-3-I-I}$ & $\mathbf{F}_{5}$ & I6I & $41.98 \pm .12$ & $2.30 \pm .09$ & $5.49 \pm .2 I$ \\
\hline No. $\left(330 \times 3^{83}\right)_{2-6-2-I}$ & $\mathbf{F}_{5}$ & I 25 & $87.88 \pm .33$ & $5 \cdot 5^{2} \pm .24$ & $6.28 \pm .27$ \\
\hline
\end{tabular}

Examination of the $F_{2}$ frequencies shows that only one individual reaches the lower size limit of No. 330 and that no individual comes within two classes of the upper size limit of No. $3^{8} 3$. Viewed from this standpoint the results are less in accord with Mendelian theory than any of those obtained in the numerous size studies I have made. At the same time, one may say that this is because the numbers are too small to expect an exact duplication of the grandparents in a species which in all probability has 24 chromosomes in its germ-cells and in which grandparental duplication should be expected only once in 265 million millions of $F_{2}$ individuals. The difficulty here would be not to account for the non-appearance of the grandparental sizes in $F_{2}$ populations of about 200 individuals, but to conceive how extremes differing by 36 millimeters had arisen. One appears to have but a single alternative: either the differences between types that give fertile $F_{1}$ generations are due to relatively few factors, the remaining germ-plasm being identical, 
or the extremes recovered are not like the grandparents but merely resemble them.

From another standpoint the variability of the $F_{1}$ and the $F_{2}$ generations is very different. Theoretically if recombination is possible, the number of classes between the extremes varies directly with the square root of the number of individuals involved. The coefficients of variability of the two populations, however, should not change with larger numbers except as regards the confidence to be placed in the calculated constants. The coefficient of variability of the $F_{1}$ generation is 4.60 . $\pm I 7$ percent and the coefficients of variability of the two $\mathrm{F}_{2}$ populations grown are $8.75 \pm .29$ percent and $9.73 \pm .30$ percent, respectively. Thus the average variability in $F_{2}$ is just double that of the $F_{1}$ generation.

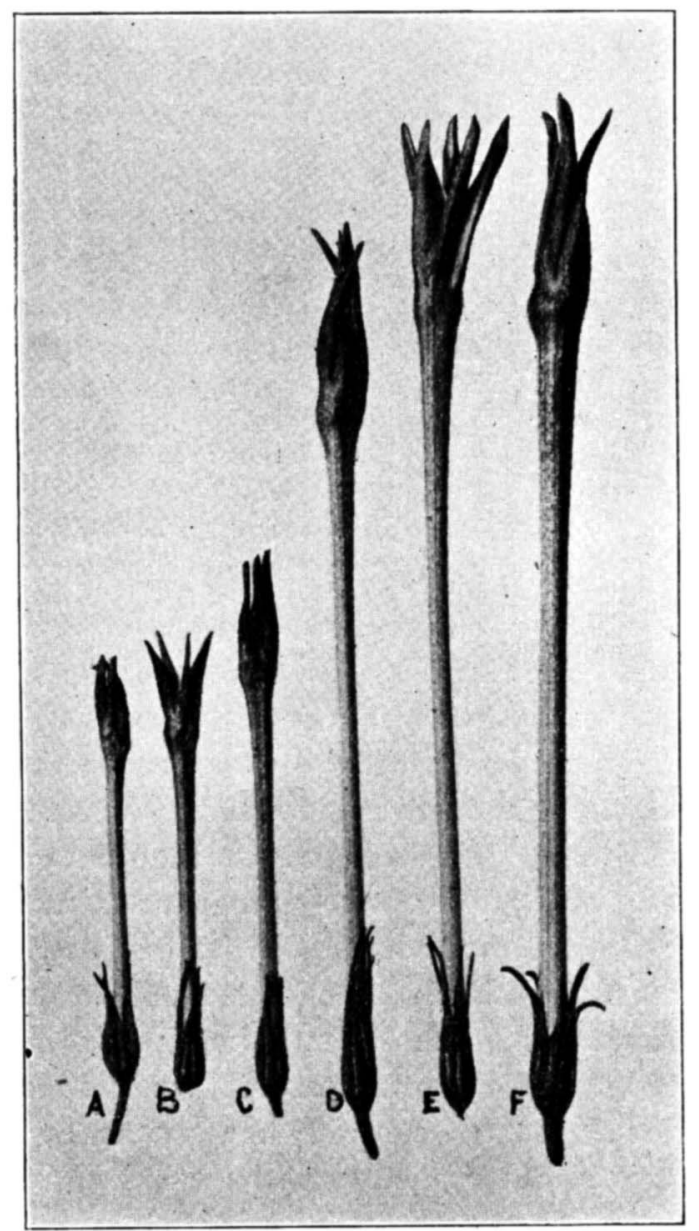

Figure 4. Average flower of No. 383 (A) compared with modal condition (C), and with an extreme $(\mathrm{B})$, of $\mathrm{F}_{3}$ family $(383 \times 330) \mathrm{I}-3$; and, ditto No. 330 (F) compared with modal condition (D), and with an extreme $(E)$, of $F_{3}$ family $(383 \times 330) 2-6$. 
One can scarcely appreciate the significance of this immense difference until he recalls that the difference between the means of the pure varieties and the mean of the $\mathrm{F}_{2}$ generation is only about four times the standard deviation of the latter, while the difference between the means of the varieties and the mean of the $F_{1}$ generation is about nine times its standard deviation.

Let us now examine the means of the populations that have resulted from selfing selected individuals of the $F_{2}, F_{3}$ and $F_{4}$ generations. Whether one can isolate rapidly lines with markedly different mean values after a blend such as occurred in the $F_{1}$ generation is a question of considerable practicable importance. Nine $F_{3}$ populations were grown. The extreme parental types from which they were grown were $46 \mathrm{~mm}$ and $82 \mathrm{~mm}$, a difference of $36 \mathrm{~mm}$. The greatest mean difference between the $F_{3}$ populations was $30 \mathrm{~mm}$, although it happened that the difference between the parents that produced these two lines was only $3^{2} \mathrm{~mm}$.

From the $F_{3}$ generation two "short corolla" and two "long corolla", lines were grown. In this generation it was possible to select extremes a little farther apart, $43 \mathrm{~mm}$ to be exact. The difference between the means of the most extreme resulting populations was $37 \mathrm{~mm}$.

Only two $F_{5}$ populations were grown, one from a plant with flowers $4 \mathrm{I} \mathrm{mm}$ long and the other from a plant with flowers $90 \mathrm{~mm}$ long. The families to which they gave rise had means of 42 and $88 \mathrm{~mm}$ in round numbers. Thus a relatively small number of selections has given a type averaging but two millimeters longer than the smaller parent, and a type averaging less than five millimeters under that of the larger parent. To attain these ends only twelve families from extreme parents were grown. It is impossible to say just how many selections of $F_{2}$ individuals would have had to have been made to reach the same goal on the recombination theory, but one can estimate the probability of the occurrence of individuals of the desired size in $F_{2}$ from which to select. Consider the $\mathrm{F}_{2}$ generation in which the standard deviation is $6.79 \mathrm{~mm}$. Assuming this distribution to be normal the expected frequency beyond the distance from its mean represented by one-half the mean of No. $33^{\circ}$ minus mean of No. 383 is .06I9 percent. In other words, one might expect an $\mathrm{F}_{2}$ individual with the size of the modal class of either grandparental variety about once in every I60o plants.

These facts indicate clearly the proper procedure of the plant breeders in such cases, as has already been brought out by EMERSON and EAST (1913). If it is technically possible to grow an $F_{2}$ large enough to be reasonably certain of obtaining several individuals with the desired com- 
bination, the breeder is tolerably sure of success. But the numbers are often prohibitive in practice, and at the best the work involved is great. On the other hand, though success is not so certain because the plants with the gametic possibilities desired may be dropped out at any point, selection continued for several generations gives a high probability of success with comparatively little work.

A study of these means with reference to their bearing on Galton's Law of Regression is also interesting.

In thirteen out of the fifteen fraternities descended from the two $F_{2}$ populations there was regression towards the mean of the fraternity from which the parent came; these two individuals, however, produced populations with means further removed from the means of the parental population than were the parent individuals themselves. Further, the deviations of the parents from the mean of their fraternity show no correlation with the deviation of the mean of the progeny from the parental value. In other words, in selfed lines of this kind an extreme variant is almost as likely to produce a type like itself as is a slight variant. This is to be expected with the hypothesis of plural segregating factors but not with the old Galtonian hypothesis in which somatic resemblance is the sole measure of heredity. Our observation is not new since Galtonian regression in the original sense is now entirely discredited, but our data illustrate the point.

The remaining arguments are based upon the variabilities of the fifteen fraternities whose means have just been considered.

In the first place, it is essential that one should know whether he may expect to obtain fraternities that breed as true as the parental varieties at once, after long continued selection, or not at all. These data do not show fraternities comparable to either parent variety in variability among the nine $F_{3}$ families, but out of the four $F_{4}$ families two show as narrow a variability as No. $3^{8} 3$.

A more important question, however, is that of continuous reduction of the coefficient of variability due to the automatic tendency toward complete homozygosis produced by continued self-fertilization. Theoretically, a fraternity produced by self-fertilization may be as variable as the fraternity from which its parent came, but it can never be more variable, provided breaks in any linkage between characters are equally probable in both cases. Of course when dealing with small populations one should not place too much confidence in the probable error calculated for any particular biometrical constant. If one could be certain that the calculated coefficient of variation represented the true values in 
TABLE 3

The pedigrees of the families and their coefficients of variation.

\begin{tabular}{c|c|c|c}
\hline$F_{2}$ & $F_{3}$ & $F_{4}$ & $F_{5}$ \\
\hline \multirow{2}{*}{$8.75 \pm .29$} & $\left\{\begin{array}{l}5.22 \pm .19 \\
6.99 \pm .28\end{array}\right.$ & $5.18 \pm .18$ & \\
$6.31 \pm .25$ & $4.04 \pm .14$ & $5.49 \pm .27$ \\
$7.22 \pm .26$ & & \\
$6.85 \pm .26$ & & \\
$6.63 \pm .26$ & & \\
$6.55 \pm .24$ & $5.74 \pm .22$ & $\left\{\begin{array}{l}4.01 \pm .14 \\
7.04 \pm .26\end{array}\right.$ & $6.28 \pm .27$ \\
\hline
\end{tabular}

a series of populations of this kind a single coefficient of variation higher than that of the preceding generation would be a critical failure of the theory of plural Mendelian determiners to meet the breeding facts. In small populations from one hundred to three hundred, however, the matter can only be tested by induction from a large number of experiments. Table 3 is a contribution toward this end. Among the fifteen families reported there are two exceptions to the rule which are noted by bold-faced type. The remainder of the families all show lower variabilities than the families from which they came.

Considering these data apart from other known facts, one may say that the evidence tends to justify the use of plural segregating factors in interpretating size inheritance, nevertheless the writer believes that dogmatic conclusions on such a broad question should not be drawn from a single set of experiments. Only when the numerous size studies of such investigators as Belling, Castle, Daven port, East, Emerson, Hayes, Heribert-Nrlsson, Kajanus, MacDowell, Nilsson-Ehle, Pearl, Phillips, Punnetr, Shull, Tammes, and Tschermak are considered together, is it possible to make a reasonable judgment of the mechanism by which such characters are transmitted. The volume of this work is large and the data reported, without exception, can be interpreted as Mendelian. Furthermore, such an interpretation is not merely formal, as some writers have stated, but is as genuinely helpful to the breeder as is any Mendelian data.

In view of these facts many biologists may question the desirability 
of increasing the literature by papers of the same type. They may hold with considerable justice that the case has been proven. At the same time, though one may not question the value of any of these investigations, it must be admitted that the material used in most of them is undesirable for a critical test of the theory involved. In all of the zoölogical researches, bisexuality introduces a constant error into the results. Many of the races of plants involved were markedly heterozygous. The difficulty of drawing just conclusions from the botanical investigations was also increased by the use of characters affected strongly by environmental differences. For these reasons, I hope to report the results of several other studies of this kind in which the constant errors are reduced to a minimum, believing that the theory must be proven or disproven under such critical conditions. If with such material the Mendelian notation is justified-as I believe is true when one considers the work of Belling, Emerson, Hayes and myself on plants naturally selffertilized-then it will be impossible to criticize its use in those experiments where some allowance must be made on account of the peculiarities of the material involved.

\section{LITERATURE CITED}

Castle, W. E., I9I4 Multiple factors in heredity. Science, N. S. 39:686-689.

EAST, E. M., I916 Significant accuracy in recording genetic data. Amer. Jour. Bot. (in press).

Emerson, R. A., and EAST, E. M., IgI3 The inheritance of quantitative characters in maize. Neb. Agr. Exp. Sta., Research Bull. No. 2, pp. I-I20.

Hayes, H. K., and EAst, E. M., IgI5 Further experiments on inheritance in maize. Conn. Agr. Exp. Sta., Bull. I88, pp. 'I-3I.

Setchels, W. A., Igiz Studies in Nicotiana I. Univ. of Cal. Pub. Botany 5:I-86. 